\title{
Application of Hand, Head and Heart: Going the Extra Mile
}

\author{
${ }^{1}$ Mr. Santosh Dwivedi, ${ }^{2}$ Dr. Ruchi Sao, ${ }^{3}$ Mr. Parag Gokhale \\ ${ }^{1}$ DGM, Corporate HR, Solar Industries India Ltd. \\ ${ }^{2}$ Assistant Professor, Shri Ramdeobaba College of Engineering and Management, Nagpur \\ ${ }^{3}$ Assistant Manager, Corporate HR, Solar Industries India Ltd. \\ Email:santosh@solargroup.com,saorn@rknec.edu,corphr1@solargroup.com
}

Received: $20^{\text {th }}$ September 2018, Accepted: $11^{\text {th }}$ October 2018, Published: $31^{\text {st }}$ October 2018

\begin{abstract}
This paper attempts to establish a connection between work culture and performance of employees. The trend started during the industrial revolution. In Manchester, United Kingdom, was involved majorly in making fabrics for garments. Manchester came to be known as biggest industrial hub. The workers were driven to perform and were using their skills with hands to finish the tasks. Thought the quality of work was very good, the time required was a bit lengthy. Then, came the phase where United States adopted time and motion study and defined each step in the process minutely. This phase came to be known as use of hands and head both. Later, Japanese companies wanted to become the market leaders in the field of world class manufacturing. They thought about improvement of processes and realized the fact that the employees need to be devoted to their work and apply their heart. Japanese companies became the leaders in world class manufacturing with the motto of use of hand, head and heart.

Application of head leads to satisfaction of heart. The target of all companies today should not be mere attendance of employees at work for 8 hours. Times have changed and so we need to change perspectives. Every data needs to be in quantifiable nature wherein KRA's are created and measured.

The paper will discuss areas of concern which will help organizations to improve in terms of quality and employees in term of belongingness and performance.
\end{abstract}

\author{
Keywords \\ Culture, Performance, Problem Solving, Quality Improvement, Task Achievement
}

\section{Introduction}

During the industrial revolution, there were a lot of changes in the field of manufacturing processes. However, many companies in various countries were in the transit period due to which some industries were trying to change in terms of technology. During this period, Manchester was majorly involved in making fabrics for garments. Manchester came to be known as biggest industrial hub in the textile sector. The workers were driven to perform and were using their skills with hands to finish the tasks which became their unique selling point in the business. They became leading exporters of the end products. However, these products were hand crafted due to which time and energy required from the workers was very high. Thought the quality of work was very good, the time required was a bit lengthy. This period saw use of 'hand' which means that skills were used abundantly but probably not with precision and in the right direction.

United States tried to use the same process used in United Kingdom but with a different application. They adopted time and motion study and started defining each step in each process minutely. They tried to calculate the exact time required and the kind of skills and worker required. A lot of machines were used. The workers were given plans and instructions which resulted in involvement of leaders who have instructions and guidelines to the workers. This phase can be aptly called as a phase wherein the involvement of a supervisor playing the role of leader and the worker in there together. In other words, United States started using 'head' with the 'hand'. In continuance with Manchester, United States entered in the business of textiles, but with the use of machines and more supervision. The tree of US grew with hand and head.

Japanese companies are known in the field of world class manufacturing. What was going on in the global business scenario caught eyes of Japanese companies and they thought about the factor which was missing. Japanese companies are known as world class manufacturers. They strive for improvement of processes and realize the fact that employees need to be devoted to their work and apply their 'heart'. The tree of Japan grew taller than US and UK. For instance, Toyota company came up with the concept of 7 wastes:

- Overproduction,

- Transportation,

- Waiting,

- Excessive inventory,

- Inappropriate processing,

- Defects and

- Unnecessary motion. 
The eighth waste that was identified with respect to human resources was 'underutilization of employee skills'. Whatever products or services came from Japanese companies was world class. The secret identified was inclusion of 'heart' with hand and head. Japan started making cars and shipped them to US for sale. To the utmost surprise, cars manufactured in Japan performed and sold better than the cars manufactured in US. It was a turnaround for Japan. They applied the theory of 'apply head and heart will be satisfied'. Feeling of satisfaction will come to workers and employees when they get an opportunity to improve the processed under the complete guidance of leader. Even, if the workers are tired and they are given targets which are directly associated with the vision of the company, they will contribute. This contribution when acknowledged would never let the employee feel job burnout or low commitment towards the organization. Thus, a complete fusion of hand, head and heart is the secret of a successful and sustainable business.

At work, people come with aspirations and doubts. If you are able to help other clear their doubts and difficulties, you would feel good and satisfied. One feels that he / she can help someone. Even when tired, the employees would help each other. For instance, if the leader delegates work to one of the subordinates with an expectation to complete it an hour; the immediate response can be: "This work would take at least a day!" But, if the employee is using his heart to the work, he would understand the urgency for the work and would not drag the same. In fact, after an hour the employee would realize that the work was easy and could have been done.

It is important that each employee gets Key Responsibility Area (KRA) identified for oneself. Even if the organization does not have such a method, the employees can have it for themselves. Instead of a 9 to 5 job, if the employees think about the involvement and improvement in processes; it would result in improvement in work and systems both.

\section{Material and Methods}

The research paper is based on conceptual study which is coupled with experience, observation and trends of the authors. The study aims at identifying the connection between $3 \mathrm{H}$ which is application of hands, head \& heart theory with improvement of business processes, jobs \& systems. The paper discusses the phases of industrial revolution with focus on three countries including United Kingdom, United States and Japan.

The objectives of the study are:

- To explore the possibilities of application of heart to workplace.

- To understand the relation between KRA's and quality improvement processes.

- To identify the ways in which companies can become market leaders in terms of manufacturing and other sectors with the help of human resources

- To identify the need of a greater number of quantifiable jobs which help in putting data in numbers.

This study will be beneficial for the manufacturing and service-oriented organizations to understand the importance of inputs which help in the best and timely achievement of the mission and vision of the organization. Concepts like key process input variables, key process output variables would be discussed in the paper.

The paper also identifies a strong association in identification of goals in the SMART framework with the 7 mantras of success which contributes to the success of the organization. Problem solving, and task achievement are the two key parameters which focus on maintenance and improvement respectively. The entire paper is written with the objective of identification of problem areas and identification of focus solutions at the grassroot levels which can be managed by the lower level management. The top management needs to work for the task achievement which will penetrate down the hierarchy in the organization.

\section{Results and Discussion}

As we have discussed about the theory of 'hand, head and heart'; it is important that the employees get an opportunity to apply their head in the organizations. If directive style of leadership will be widely spread in the organization, it would be difficult for the employees to think of improvement in the processes and otherwise. Thus, a free hand and autonomy needs to be given to the employees to set their own targets and goals which should be in the SMART framework.

$\mathrm{S}-$ Specific

$\mathrm{M}$ - Measurable

A - Attainable

$\mathrm{R}-$ Realistic

$\mathrm{T}$ - Time bound

Not only that the goals should be as per the SMART framework, they should also be documented and reviewed on regular basis. The KRA's identified should be updated and reviews must be done.

In majority of the manufacturing firms, 7 mantras of success (PQCDSME) are identified, namely;

- Productivity,

- Quality,

- Cost optimization, 
- Delivery on time in full,

- Safety,

- Morale and

- Environment

In the field of data analytics, we generally divide the processes into two parameters which are:

\section{- $\quad$ Key Process Input Variable (KPIV):}

KPIV covers the last three mantras of success which are Safety, Morale and Environment. Majority of the organization fail to understand and accept that the input factors are the most important. It is the care for the employee in the form of safety, employee morale and creation of a conducive work environment which would help the employees give their best performance.

\section{- Key Process Output Variable (KPOV):}

KPOV generally covers the first four Productivity, Quality, Cost optimization and Delivery on time in full. The best performance discussed under KPIV will results in achievement of the output which helps the organisations to achieve their goals and financial strength.

In case of a typical manufacturing company, if you ask a production head what his job is, the answer would be that he would plan the production and ensure timely output. The same question if asked to a production manager, shift in-charge, supervisor or a worker; the answer would be near about the same. However, if a worker is asked that if he is producing what is the machine doing? His reply may change, and he may say that the worker is only operating the machine. In this case, if we go by the theory of hand, head and heart; the worker is probably only using his hands. Across the hierarchy, every designation is working as per the standards and methods prescribed. But, the job of employees is not only to work, but to improve the work. What bought the employee till this designation will not take him further if he dies the same kind of work. The question that the organizations need to ask today is "How to transfer processes to improve?"

For routine jobs, employees do not apply their head. If an employee is drafting a letter, he would directly start with salutation and greetings. The head is trained depending upon the kind of work one has been doing since a long time. If the organizations want to move to world class manufacturing, the solution is to increase the ability to improve the work. There are various ways in which improvement can be done such as Quality Circles, Total Productive Maintenance, Lean Management, Six Sigma and so many more. The problem itself is a solution. One must start with improvement of processes done at individual level resulting into departmental and system level improvements.

The problem is that majority of the organizations do not talk in numbers. The biggest difference between a playground and office is that there is a scoreboard at the playground. In organizations, we do not have a scoreboard for all designations. What if all employees start creating their own scoreboard? It is high time that the employees set their own benchmarks. Many employees who have spent a considerable duration at in the same organization, crib over an average increment or that they do not get promotion. But the question is how many employees really deserve a good increment or promotion? The need is to make a PDCA (plan, do, check, and act) for all. There are ways in which communication can be done by the leader and message can be passed instead of highlighting the mistakes.

For every job, managers need to talk in terms of numbers. They are not supposed to pass judgements. More numbers are involved, higher is the possibility that rating errors, or any other error will be eliminated. Numbers are an international language today.

\section{Conclusion}

If one must play in business to win, following the number theory is very important. Sincere attempts to links SMART goals with numbers would surely help in process improvement across the hierarchy. The meetings and reviews need to take place based on numbers. The complete fusions need to be there. Numbers will help to bring in management by facts resulting in enhanced and sustained performance. The difference that the employee needs to understand today is between 'Available' and 'Desired'. We should focus on improvement rather than just finishing the task at a single point of time. Improvement has two parts:

\section{- Problem Solving}

The focus should be on identification of problem and finding the solution. There can be issues with respect to noncompliance, not proper use of systems and processes, errors or negligence. Thus, getting back to the perfect benchmark and identifying solutions to reach the benchmark should be the task of the employee. The employees may create problems due to non-maintenance and they are the one who will be instrumental in creating solutions to the problems. The lower level management should focus on problem solving approach. This approach will be more for maintenance. 


\section{- Task Achievement}

The task achievement is generally addressed as that of improvement process. The task achievement needs to be addressed by the middle and top-level management. The process of task achievement directly aims at creating a new benchmark for various functions across the organization hierarchy.

The organization needs to get involved in constructive destruction which involves use of a process for bringing something new in terms of technology or otherwise resulting in the extinction of a process or technology which was used earlier. In organizations, this can be used for product development, technology or otherwise.

Thus, the need for maintenance, automation, improvement, use of constructive destruction and focus on KPIV aligned with $3 \mathrm{H}$ : hands, head and heart will surely increase the efficiency of employees across the hierarchy resulting in continuous and sustained growth of the organization making the organization competitive.

\section{References}

1. El-Namrouty, K. A., \& Abushaaban, M. S. (2013). Seven wastes elimination targeted by lean manufacturing case study "gaza strip manufacturing firms". International Journal of Economics, Finance and Management Sciences, 1(2), 68-80

2. Soliman, M. (2017). A Comprehensive Review of Manufacturing Wastes: Toyota Production System Lean Principles

3. Molin, P. F. (1988). "Training the Hand the Head, and the Heart": Indian Education at Hampton Institute. Minnesota History, 51(3), 82-98

4. Sipos, Y., Battisti, B., \& Grimm, K. (2008). Achieving transformative sustainability learning: engaging head, hands and heart. International Journal of Sustainability in Higher Education, 9(1), 68-86

5. Ivanaj, V., Poldner, K., \& Shrivastava, P. (2014). HAND/HEART/HEAD: Aesthetic practice pedagogy for deep sustainability learning. The journal of corporate citizenship, (54), 23 